\section{Operative Techniques to Prevent Dialysis Access- associated Steal Syndrome in High-risk Patients Undergoing Surgery for Hemodialysis Access: A Systematic Review}

\author{
Fareed A. Shaikh ${ }^{1}$, Nadeem Siddiqui ${ }^{1}$, Noman Shahzad ${ }^{2}$, Amna Riaz ${ }^{1}$, Ziad Sophie ${ }^{1}$ \\ 1. Surgery, Aga Khan University Hospital, Karachi, PAK 2. Surgery, Northern Lincolnshire and Goole NHS Foundation \\ Trust, Scunthorpe, GBR
}

Corresponding author: Noman Shahzad, drns01@hotmail.com
Received 07/10/2019

Review began 08/01/2019 Review ended 11/04/2019 Published 11/06/2019

๑) Copyright 2019

Shaikh et al. This is an open access article distributed under the terms of the Creative Commons Attribution License CC-BY 3.0., which permits unrestricted use, distribution, and reproduction in any medium, provided the original author and source are credited.

\begin{abstract}
Up to $10 \%$ of patients suffer from various degrees of dialysis access-associated steal syndrome (DASS) after surgery for hemodialysis access. This systematic review was conducted to find out optimal intra-operative techniques to prevent DASS in high-risk patients.
\end{abstract}

This systematic review is registered with PROSPERO (2017:CRD42017060804). It was conducted at Department of Surgery, Aga Khan University Hospital, Karachi. All types of studies conducted on intraoperative techniques to prevent DASS in high-risk population (Age > 60 years, female gender, diabetes mellitus, peripheral arterial disease and previous DASS) undergoing access creation from January 1990 till April 2019 were included in the systematic review. Thorough search was conducted on Pubmed, Google Scholar and Cochrane databases to identify relevant articles. Included studies reviewed for success of various techniques to prevent dialysis access steal syndrome are summarized.

Out of 125 studies in the initial search, six met the inclusion criteria. Five were retrospective case series while one was a case report. The largest study sample size was 32 . All but one study had arterio-venous access creation on an arm. "Proximalization of arterial inflow" was described in three and "prophylactic distal revascularization and interval ligation (DRIL) procedure” in two studies to prevent DASS. Only one patient out of these studies developed DASS at an overall follow-up of 7-42 months.

Proximalization of inflow has been reported as the most common procedure performed to prevent DASS followed by extension technique and DRIL procedure. All three procedures have satisfactory outcome with no clear superiority of one over the other.

Categories: Cardiac/Thoracic/Vascular Surgery, General Surgery

Keywords: prophylactic intraoperative techniques, high risk patients, dialysis access associated steal syndrome (dass)

\section{Introduction And Background}

End stage renal disease (ESRD) affects more than 1500 people per million population per year. Approximately two-third of these undergo hemodialysis [1]. Hemodialysis access-related complications are the most common cause of hospital admissions in ESRD patients on dialysis [2]. Dialysis access-associated steal syndrome (DASS) is one of those and the most dreadful complication which affects up to $10 \%$ of high risk patients [3, 4]. Traditionally, after arterio-venous (AV) access surgery if someone develops DASS, remedial surgery is offered which ranges from salvage procedures usually "distal revascularization and interval ligation - DRIL Procedure” to reciting of AV access. Certain features have been identified that put patients at high risk for developing DASS. These include age more than 60 years, diabetes mellitus, female gender, peripheral arterial disease, and history of previous DASS [3-6]. In these high-risk patients simultaneous prophylactic procedure to prevent DASS along with index AV access surgery for haemodialysis has been reported to reduce the morbidity [7-10]. These prophylactic surgical techniques include "Proximalization of arterial inflow", "Extension technique” and "Prophylactic DRIL" [7-9].

Proximalization of arterial inflow as shown in Figure 1 works by taking inflow of the fistula from proximal larger diameter artery (Axillary artery) hence providing adequate blood to both the fistula and distal limb by virtue of higher blood flow [11,12]. Moreover it also adds to the length of outflow segment and the needling site when reversed basilic vein is used [8]. On the other hand, PTFE graft can also be used, but only at the cost of higher risk of infection and thrombosis [13]. Song and Yun described inflow from sub-scapular artery, which has advantage of proximalization as well as avoiding the main arterial inflow to the limb [13]. 


\section{Cureus}

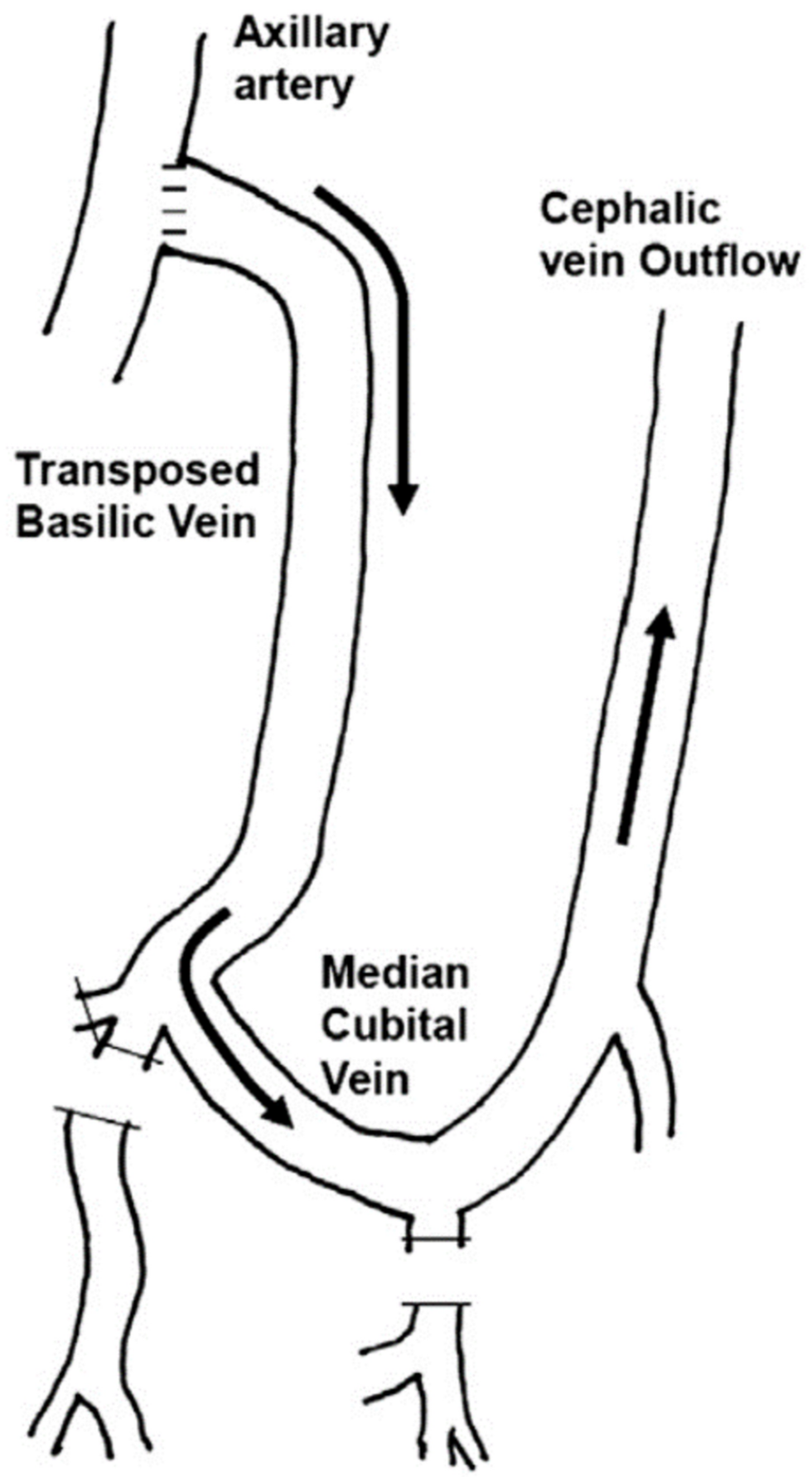

FIGURE 1: Proximalization of arterial inflow.

In the extension technique, instead of taking inflow from brachial artery, one of the forearm arteries is used $2-3 \mathrm{~cm}$ distal to bifurcation of brachial artery to anastomose with ante-cubital vein as given in Figure 2 [7]. The perfusion of distal limb is kept intact via the other artery of forearm. It takes 10-15 minutes more than simple brachio-cephalic AV fistula. In addition, it has the additional benefit of maturing both the cephalic and basilic veins simultaneously [7]. 


\section{Cureus}

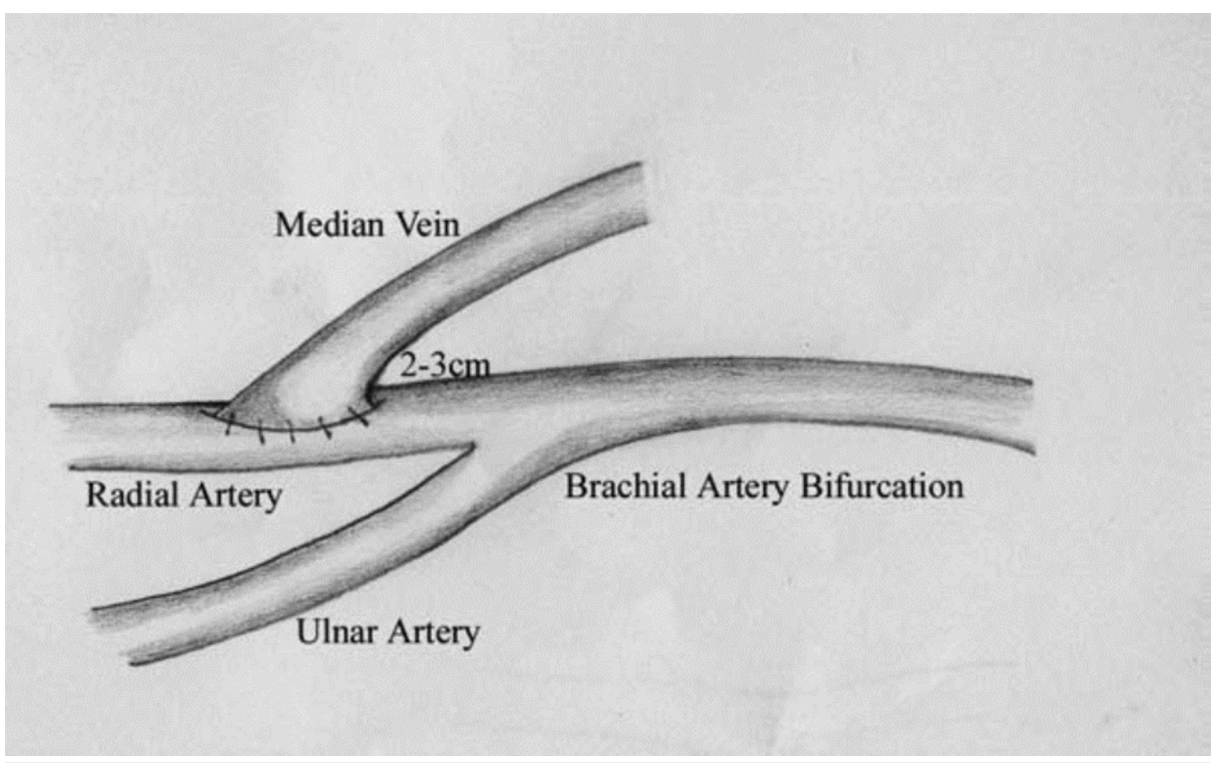

FIGURE 2: Extension technique.

The principle of prophylactic DRIL (Distal Revascularization and Interval Ligation) remains same when it is applied for treatment of DASS, i.e., both the fistula and distal limb are perfused simultaneously and reversal of flow is prevented by interval ligation, as depicted in schematic diagram (Figure 3) [14]. It was first described by Schanzer et al. in 1988 with a technical success of $90 \%$ and bypass patency of $80 \%$ at four years [15]. Despite all this, one of the major limitations of DRIL procedure is that the native artery is ligated and the limb perfusion is dependent upon bypass graft, which itself is at risk of complications [10]. However, Nader et al. and Leake et al. did not show additional morbidity related to procedure.

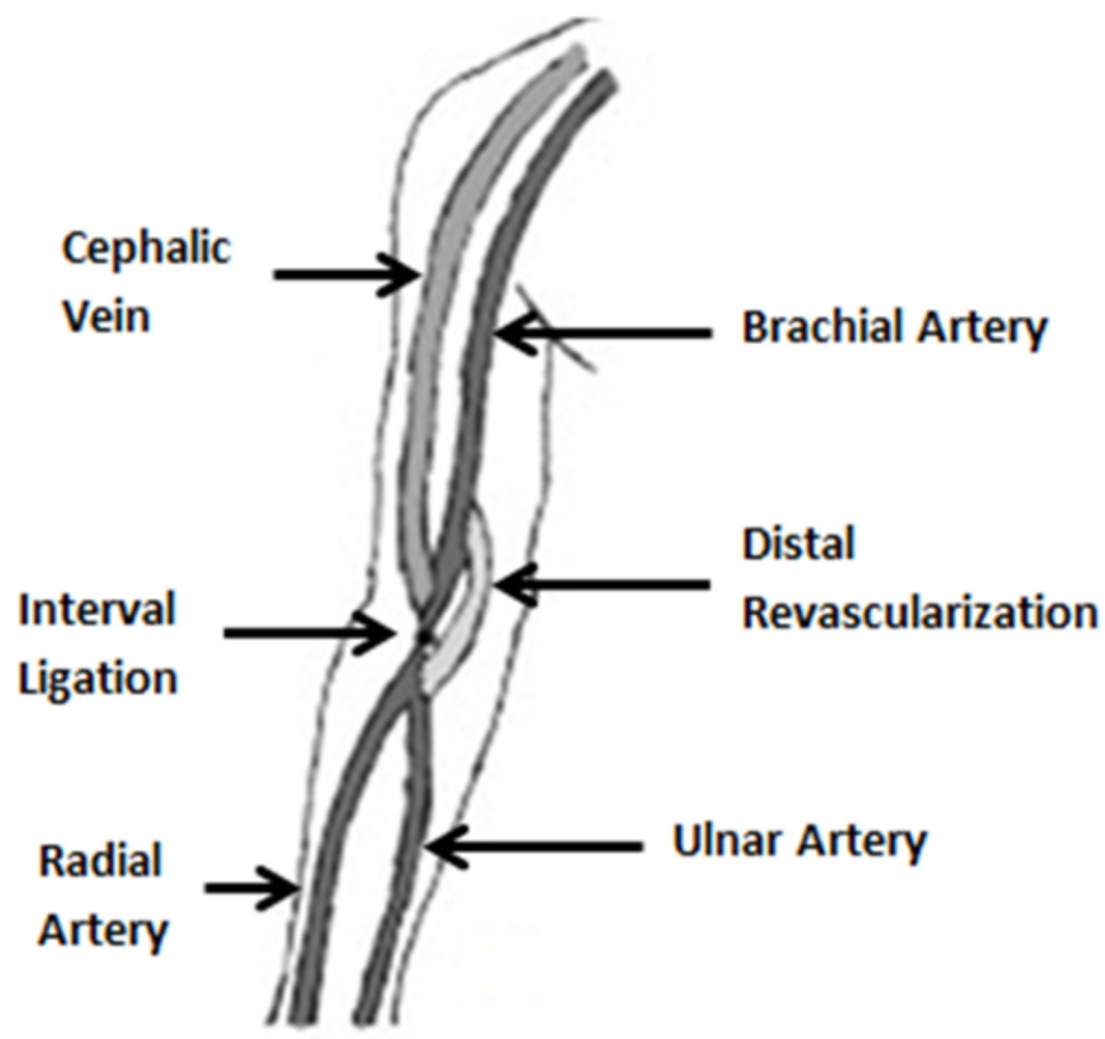

FIGURE 3: Distal revascularization and interval ligation.

Comparative efficacy of these techniques is not known [7-9]. 


\section{Objective}

This systematic review was conducted to review and compare outcome of various prophylactic surgical techniques performed along with primary AV access surgery for hemodialysis to prevent dialysis access steal syndrome (DASS) in high-risk patients.

\section{Review}

This systematic review is registered with PROSPERO (2017:CRD42017060804). We searched for all types of studies including case report, observational studies and interventional trials that reported prophylactic intra-operative techniques to prevent DASS in high-risk patients undergoing hemodialysis access procedure. We considered studies published from January 1990 till March 2017. Studies published in languages other than English, performed on animals or un-published reports were excluded. A thorough systematic search for relevant studies was done on Google scholar, PubMed and Cochrane Database and the last date of search was April 30, 2019.

In order to identify relevant studies, the search strategy was based upon concepts of population, intervention and outcome. Population was identified as adults with end stage renal disease (ESRD), high risk for DASS, and requiring permanent hemodialysis access. Search terms used to look for population of interest were "high risk" OR "prone to" OR "females more than 60 years of age" OR "diabetics" OR "peripheral arterial disease" AND "Arterio-venous fistula” OR "AVF” OR "Hemodialysis Access" OR "AVBG" OR "Brachiocephalic fistula" OR "Basilic transposition fistula" OR "Brachio-basilic fistula". Intervention of interest was prophylactic intra-operative techniques to prevent DASS for which we used "Prophylactic" OR "Pre-emptive" OR "Preventive” OR “Intra-operative” OR "Per-operative” AND “Techniques" OR "Steps" OR "procedure" OR "Extension technique" OR "DRIL" OR "Proximalization of inflow" OR "RUDI" as relevant terms. Outcome was identified using "Dialysis access steal syndrome" OR "steal syndrome" Or "distal ischemia".

Using relevant search terms for individual concepts, two investigators separately searched and reviewed the literature. If there was any disagreement between two, the third investigator was involved. Initial screening for inclusion was done reading the title of the studies and identifying duplicates. Further eligibility according to selection criteria was done through stages of abstract and full manuscript evaluation. References of included studies were also searched to identify any missing reports. Specifically designed data extraction sheet was used to collect the data from individual studies. Information such as first author's name, journal, year of publication, study design, country of origin, target population, prophylactive intraoperative technique used, sample size/number of cases, site of arteriovenous fistula, mean follow-up in months, dialysis access steal syndrome were extracted from studies.

\section{Results}

A total of 125 studies were retrieved after applying search strategy, out of those six met the inclusion criteria as summarized in Figure 4. 


\section{Cureus}

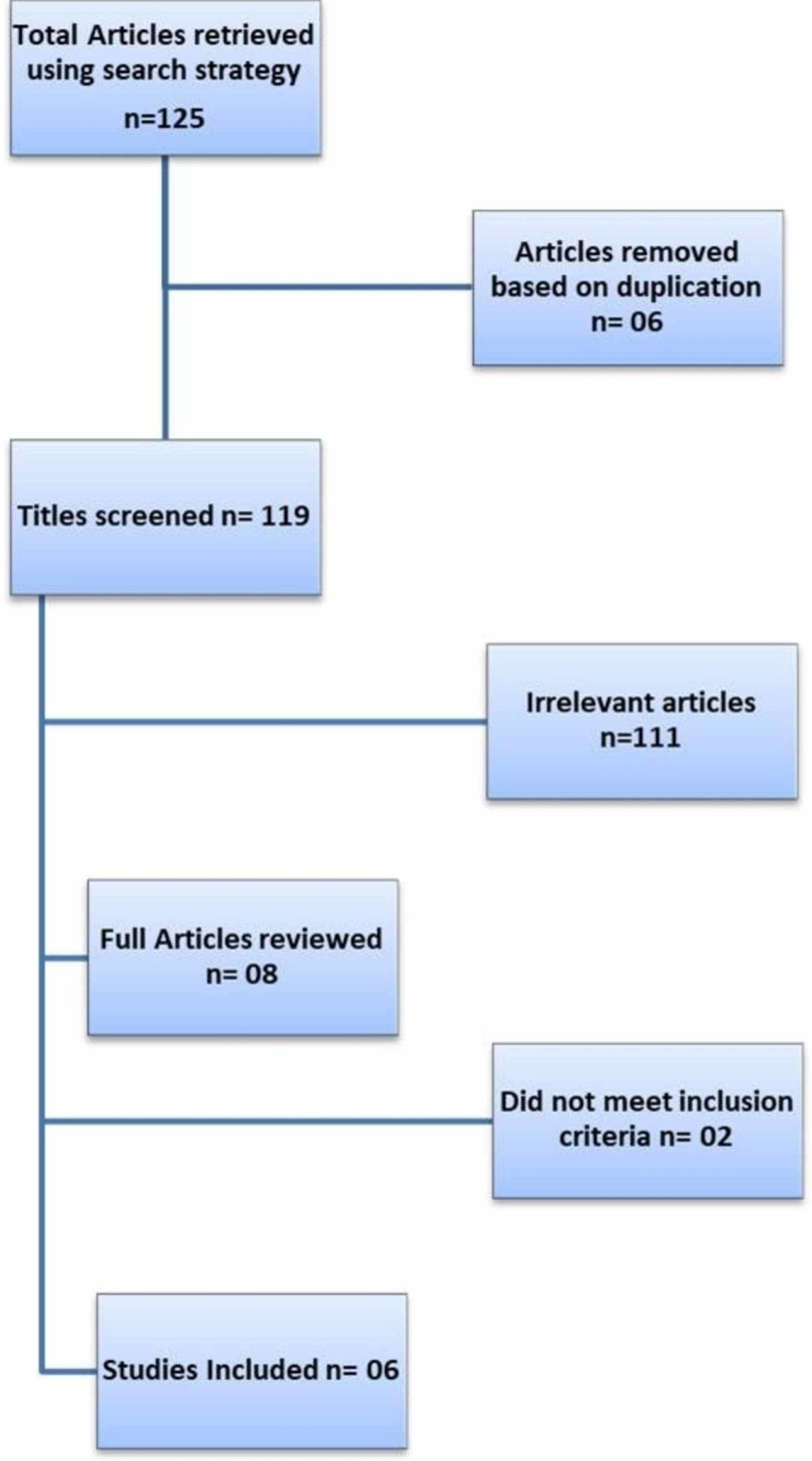

FIGURE 4: Flow diagram for selection of studies (PRISMA Diagram).

Majority of studies were retrospective case series while only one was a case report. The largest study sample size was 32 in one of the case series by Ehsan et al. [7]. Five studies involve AV access creation on arm whereas one by Nader et al. has described AV access in thigh [10]. Intra-operative techniques described were variable. "Proximalization of arterial inflow" was described in three, "prophylactic DRIL" in two whereas "Extension technique" was reported in one study to prevent DASS (Table 1). 


\section{Cureus}

\begin{tabular}{|c|c|c|c|c|c|c|}
\hline Author (Year) & Journal & Study design & $\begin{array}{l}\text { Sample } \\
\text { size }\end{array}$ & Population & Intra-operative technique & Country \\
\hline $\begin{array}{l}\text { Ehsan et al. } \\
\text { (2005) [7] }\end{array}$ & $\begin{array}{l}\text { Eur J Vasc } \\
\text { Endovasc Surg }\end{array}$ & Case series & 32 & $\begin{array}{l}\text { High risk for } \\
\text { DASS }\end{array}$ & Extension technique & $\begin{array}{l}\text { United } \\
\text { Kingdom }\end{array}$ \\
\hline $\begin{array}{l}\text { Jennings et al. } \\
\text { (2011) [8] }\end{array}$ & J Vasc Surg & Case series & 04 & $\begin{array}{l}\text { High risk for } \\
\text { DASS }\end{array}$ & Proximalization of inflow & USA \\
\hline $\begin{array}{l}\text { Jennings et al. } \\
\text { (2013) [11] }\end{array}$ & J Vasc Surg & $\begin{array}{l}\text { Retrospective } \\
\text { audit }\end{array}$ & 30 & $\begin{array}{l}\text { High risk for } \\
\text { DASS }\end{array}$ & Proximalization of inflow & USA \\
\hline $\begin{array}{l}\text { Nader et al. } \\
\text { (2013) [10] }\end{array}$ & Ann Vasc Surg & Case series & 02 & $\begin{array}{l}\text { High risk for } \\
\text { DASS }\end{array}$ & Prophylactic DRIL & USA \\
\hline $\begin{array}{l}\text { Song \& Yun } \\
\text { (2015) [13] }\end{array}$ & $\begin{array}{l}\text { Ann Surg Treat } \\
\text { Res }\end{array}$ & Case report & 01 & $\begin{array}{l}\text { High risk for } \\
\text { DASS }\end{array}$ & $\begin{array}{l}\text { Proximalization of inflow (Sub- } \\
\text { scapular artery) }\end{array}$ & Korea \\
\hline $\begin{array}{l}\text { Leake et al. } \\
\text { (2015) [9] }\end{array}$ & $\begin{array}{l}\text { JVasc Surg } \\
\text { Cases }\end{array}$ & $\begin{array}{l}\text { Retrospective } \\
\text { Case series }\end{array}$ & 05 & $\begin{array}{l}\text { High risk for } \\
\text { DASS }\end{array}$ & Prophylactic DRIL & USA \\
\hline
\end{tabular}

TABLE 1: Characteristics of the studies included in the systematic review.

DASS: Dialysis access-associated steal syndrome; DRIL: Distal revascularization and interval ligation.

Follow-up ranged from seven to 42 months as shown in Figure 5. Only one patient in a case series by Ehsan et al. developed DASS which required correction, while none of the patients in other studies developed this complication after prophylactic procedure (Table 2) [7].

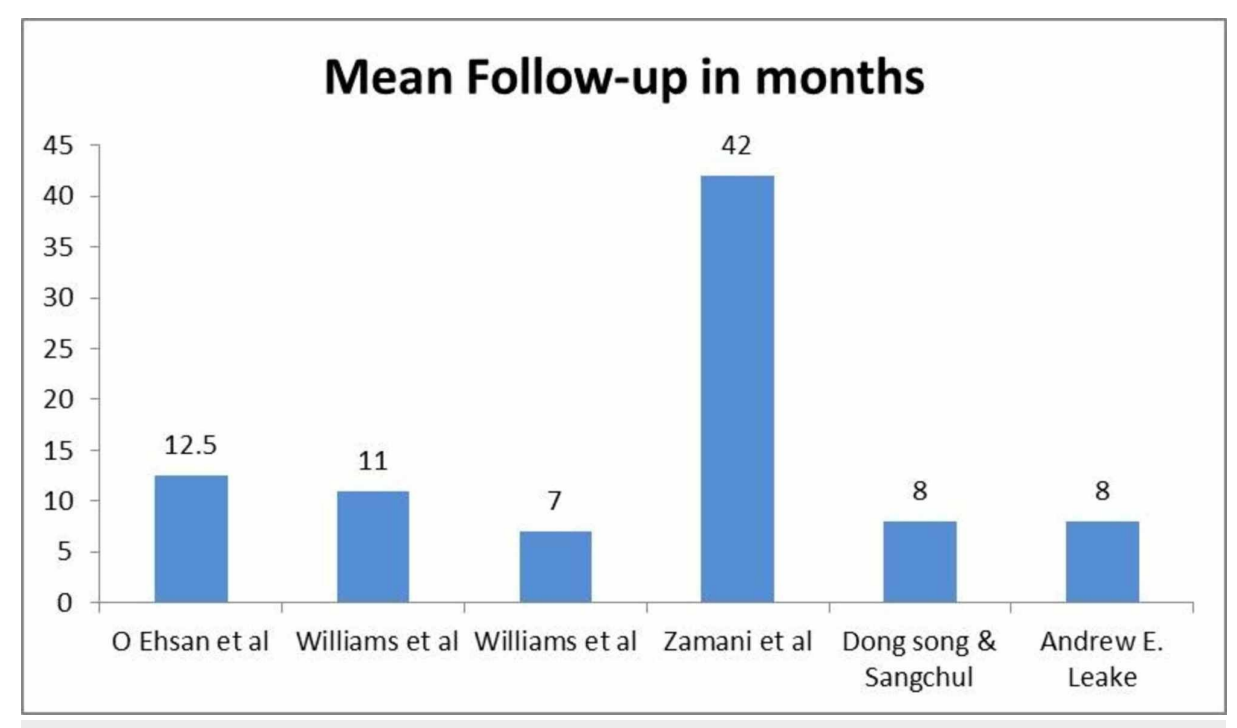

FIGURE 5: Mean follow-up of patients in included studies. 


\section{Cureus}

\begin{tabular}{|l|l|l|}
\hline Author (Year) & Sample size / No of cases & DASS \\
\hline Ehsan et al. (2005) [7] & 32 & $01(3.1 \%)$ \\
\hline Jennings et al. (2011) [8] & 04 & 0 \\
Jennings et al. (2013) [11] & 30 & 0 \\
Nader et al. (2013) [10] & 02 & 0 \\
Song \& Yun (2015) [13] & 01 & 0 \\
Leake et al. (2015) [9] & 05 & 0 \\
\hline
\end{tabular}

TABLE 2: Dialysis access-associated steal syndrome (DASS) in included studies.

Our review found that majority of the studies favor "Proximalization of Arterial Inflow" as a useful technique to prevent DASS in high-risk patients undergoing surgery for permanent hemodialysis access, though both "Extension technique" and "Prophylactic DRIL" have also been shown to be effective in preventing DASS. These results can help vascular surgeons in decision making regarding AV access in high risk patients.

Due to lack of large sample studies and retrospective nature of studies, quality of evidence available is low.

\section{Conclusions}

Proximalization of inflow has been reported as the most common procedure performed to prevent DASS followed by extension technique and DRIL procedure. All three procedures have satisfactory outcome with no clear superiority of one over the other.

\section{Additional Information \\ Disclosures}

Conflicts of interest: In compliance with the ICMJE uniform disclosure form, all authors declare the following: Payment/services info: All authors have declared that no financial support was received from any organization for the submitted work. Financial relationships: All authors have declared that they have no financial relationships at present or within the previous three years with any organizations that might have an interest in the submitted work. Other relationships: All authors have declared that there are no other relationships or activities that could appear to have influenced the submitted work.

\section{Acknowledgements}

Dr Fathima Riziniya Mohideen Resident General Surgery Aga Khan University Hospital Karachi Email: riziniyamohideen@gmail.com She was very helpful in literature search.

\section{References}

1. Abbasi MA, Chertow GM, Hall YN: End-stage renal disease. BMJ Clin Evid. 2010, 2010:2002.

2. Feldman HI, Kobrin S, Wasserstein A: Hemodialysis vascular access morbidity. J Am Soc Nephro. 1996, 7:523-535.

3. Morsy AH, Kulbaski M, Chen C, Isiklar H, Lumsden AB: Incidence and characteristics of patients with hand ischemia after a hemodialysis access procedure. J Surg Res. 1998, 74:8-10. 10.1006/jsre.1997.5206

4. Wixon CL, Hughes JD, Mills JL: Understanding strategies for the treatment of ischemic steal syndrome after hemodialysis access. J Am Coll Surg. 2000, 191:301-310. 10.1016/S1072-7515(00)00335-5

5. DeCaprio J, Valentine R, Kakish H, Awad R, Hagino RT, Clagett GP: Steal syndrome complicating hemodialysis access. Cardiovasc Surg. 1997, 5:648-653. 10.1016/s0967-2109(97)00072-0

6. Goldfeld M, Koifman B, Loberant N, Krowll I, Haj M: Distal arterial flow in patients undergoing upper extremity dialysis shunting: a prospective study using Doppler sonography. Am J Roentgenol. 2000, 175:513516. 10.2214/ajr.175.2.1750513

7. Ehsan O, Bhattacharya D, Darwish A, Al-khaffaf H: 'Extension technique': a modified technique for brachiocephalic fistula to prevent dialysis access-associated steal syndrome. Eur J Vasc Endovasc Surg. 2005, 29:324-327. 10.1016/j.ejvs.2004.09.018

8. Jennings WC, Brown RE, Ruiz C: Primary arteriovenous fistula inflow proximalization for patients at high risk for dialysis access-associated ischemic steal syndrome. J Vasc Surg. 2011, 54:554-558. 10.1016/j.jvs.2011.01.031

9. Leake AE, Leers SA, Reifsnyder T, Dillavou ED: Prophylactic distal revascularization with interval ligation and simultaneous arteriovenous fistula creation in high-risk patients. J Vasc Surg Cases. 2015, 1:87-89. 10.1016/j.jvsc.2015.02.003 


\section{Cureus}

10. Nader Z, Anaya-Ayala JE, Ismail N, Davies MG, Peden EK: Prophylactic distal revascularization and interval ligation procedure during femoral vein transposition fistula creation in patients at high risk for ischemic complications. Ann Vasc Surg. 2013, 27:353.e7-353.e11. 10.1016/j.avsg.2012.10.008

11. Jennings W, Brown R, Blebea J, Taubman K, Messiner R: Prevention of vascular access hand ischemia using the axillary artery as inflow. J Vasc Surg. 2013, 58:1305-1309. 10.1016/j.jvs.2013.05.006

12. Zanow J, Kruger U, Scholz H: Proximalization of the arterial inflow: a new technique to treat access-related ischemia. J Vasc Surg. 2006, 43:1216-1221. 10.1016/j.jvs.2006.01.025

13. Song D, Yun S: Alternative prosthetic vascular access creation using subscapular artery as inflow to preven dialysis access related steal syndrome. Ann Surg Treat Res. 2015, 88:349-352. 10.4174/astr.2015.88.6.349

14. Polimanti AC, Galego SJ, Fürst RVdC, et al.: Treatment of hemodialysis access steal syndrome by distal revascularization arterial ligature: report of three cases. J Vasc Bras. 2012, 11:158-161. 10.1590/S167754492012000200015

15. Schanzer H, Schwartz M, Harrington E, Haimov M: Treatment of ischemia due to "steal" by arteriovenous fistula with distal artery ligation and revascularization. J Vasc Surg. 1988, 7:770-773. 10.1016/07415214(88) $90040-7$ 